\title{
Innovation Labs: Leveraging Openness for Radical Innovation?
}

\author{
Lidia Gryszkiewicz $^{1}$, Ioanna Lykourentzou ${ }^{1}$, Tuukka Toivonen ${ }^{2}$ \\ ${ }^{1}$ Luxembourg Institute of Science and Technology, Belval, Luxembourg \\ \{lidia.gryszkiewicz, ioanna.lykourentzou\}@list.lu \\ ${ }^{2}$ The Institute for Global Prosperity (IGP), University College London, London, United \\ Kingdom \\ tuukka.t@gmail.com
}

\begin{abstract}
A growing range of public, private and civic organisations, from Unicef through Nesta to NHS, now run units known as "innovation labs". The hopeful assumption they share is that labs, by building on openness among other features, can generate promising solutions to grand challenges of systemic nature. Despite their seeming proliferation and popularisation, the underlying innovation principles embodied by labs have, however, received scant academic attention. This is a missed opportunity, because innovation labs appear to leverage openness for radical innovation in an unusual fashion. Indeed, in this exploratory paper we draw on original interview data and online self-descriptions to illustrate that, beyond convening "uncommon partners" across organisational boundaries, labs apply the principle of openness throughout the innovation process, including the experimentation and development phases. While the emergence of labs clearly forms part of a broader trend towards openness, we show how it transcends established conceptualisations of open innovation (Chesbrough et al., 2006), open science (David, 1998) or open government (Janssen et al., 2012).
\end{abstract}

Keywords. Innovation labs, openness, open innovation, collaboration, open government, innovation hubs

\section{Introduction}

A growing range of public, private and civic organisations, from Unicef through Nesta to NHS, now run or support units known as "innovation labs". The hopeful assumption they share is that labs, by building on openness among other features, can generate promising solutions to grand challenges of complex, systemic nature. To highlight just a few examples, the eLab is grappling with the key challenges of the electricity sector; London's Finance Innovation Lab, showing yet more ambition, aims to rework the entire financial system, whereas the Unicef Labs innovate to alleviate the problems faced by children around the world. Recent practitioner publications, such as Labcraft (Tiesinga \& Berkhout, 2014) and i-teams (Puttick et al., 2014) have shed some light on how labs work in practice while stirring broader interest in this phenomenon.

Despite their seeming proliferation and popularisation, the underlying innovation paradigm embodied by labs has so far received scant academic attention. This is a missed opportunity, because innovation labs are potentially fruitful vehicles for 
leveraging openness for radical innovation1. Indeed, labs seek to span organisational, sectoral and geographical boundaries, welcoming a variety of actors, including representatives of business, NGOs, governments, arts, science and local communities. They claim to embrace radical ideas and out-of-the box thinking. But what are innovation labs really about? How do they differ from other innovation initiatives and intermediaries? Is the way in which labs embrace openness a key factor that defines them?

In this article, we contextualise and analyse the innovation labs phenomenon. Our focus is on how labs apply the principle of openness at different points in the innovation process. The organisational literature on openness in innovation and invention has, as we survey below, developed through the concepts of open innovation (Chesbrough et al., 2006), open science (David, 1998) and open government (Janssen et al., 2012). It has recently turned its attention to more precise questions around when openness is and is not useful for problem-solving purposes (Felin \& Zenger, 2014; Hemphälä \& Magnusson, 2012) and which stages of the innovation process should be opened up or kept closed (Laursen \& Salter, 2014). But even in light of this expanded vocabulary and range of perspectives, the innovation labs analysed in this paper add several contrasting elements, for instance through issuing open calls for participation in handson, continued innovation processes (as opposed to asking users to address well-defined, relatively simple tasks in a one-off fashion).

In terms of structure, we first illustrate the innovation lab phenomenon with four prominent examples. We then conduct a literature review of "openness" in the innovation management literature, touching also on open science and open government. Next, following a description of our methodological approach, we present our main empirical findings, focusing on openness aspects that characterise innovation labs. We then compare and contrast innovation labs with other innovation-focused organisational forms, showing that they cannot be easily subsumed under any preexisting organisational form or category. Finally, we provide a preliminary lab definition and clarify innovation labs' unique approach to openness, concluding by setting out the limitations of our work, its practical implications and the avenues for further research it points towards.

\section{Innovation labs: some examples}

In this section, we provide four innovation lab snapshots to illustrate what real-world labs do and familiarise the reader with this emergent phenomenon. A natural example to start with is the London-based Finance Innovation Lab (FIL), founded in 2008 at the height of the global financial crisis (www.thefinancelab.org). FIL builds on a diverse international community of over 2,500 people who have joined the lab voluntarily and are "committed to reworking the financial system". Members comprise a diverse mix of social entrepreneurs, bankers, activists, design students and academics, and their

\footnotetext{
${ }^{1}$ Radical innovation can be defined us "a product, process or service with either unprecedented performance features or familiar features that offer potential for significant improvements in performance or cost (...) radical innovations create such dramatic change in products, processes, or services that they transform existing markets or industries, or create new ones" (Leifer, 2000, p. 5).
} 
interactions are facilitated by the lab founders as well as host organisations such as WWF-UK (World Wide Fund for Nature) and ICAEW (Institute of Chartered Accountants in England and Wales). They regularly participate in collaborative workshops and use novel approaches such as crowdsourcing to solicit ideas that might contribute to a better financial system. They turn the most attractive proposals into projects and prototypes that the lab helps resource. To effectively orchestrate these activities, the core lab team has broadcast its transformative vision as widely as possible to attract a range of participants with different views and areas of expertise. It has learned to segment its membership into smaller teams according to individual members' readiness to collaborate and move from ideas to implementation (Jen Morgan, personal communication, 11 February 2016). At the same time, FIL has provided focused support to various new and existing financial startups that share its vision, one example of which is Abundance Investment that facilitates peer-to-peer investment into projects with positive environmental and/or social impact (https://www.abundanceinvestment.com/). Another example of tangible impact and systemic change that the lab is delivering is The Lab's Fellowship programme that "supports innovators who are building financial businesses that put people and planet first, incubating the next generation of change-makers in finance". The programme aims to build "strategic know-how, collaborative leadership skills and a community of peers who will support each other to succeed" (FIL website, 2016). This programme is as central to FIL's strategic model as its other efforts that focus on convening and advocacy, and it generates startups and other projects that implement FIL's mission in a distributed fashion.

The Colorado-based eLab is a pertinent second example. In its own words, the eLab is an "assembly of thought leaders and decision makers from across the U.S. electricity sector [that] focuses on collaborative innovation to address critical institutional, regulatory, business, economic, and technical barriers to the economic deployment of distributed [electricity sector] resources" (http://www.rmi.org/elab). As the issues in the electricity sector are "occurring at the 'seams' where no single stakeholder or industry group can control the outcome", making systemic shifts requires the innovators to work well in complex multi-stakeholder environments across traditional institutional boundaries. eLab members collaboratively explore complex issues in the electricity field, develop insights, and partner with stakeholders to test and apply new ideas. Currently, eLab is working on several ambitious topics such as Transforming How Communities Use Energy, New Business Models ("framing clear objectives and principles around the design of electricity business models, reflecting the variety of perspectives on this topic, and taking the first step towards identifying viable new models") and Shared Vision ("to orient eLab participants around a common sense of purpose, align project efforts for greatest effect, and ultimately inform and engage others"), to name just a few. One specific example of eLab's impact is eLab Leap that is currently working in New York, enabling diverse stakeholders to "form untraditional working partnerships and co-develop creative and new solutions that empower lowincome households and communities to benefit from a clean energy future" (eLab website, 2016). Community Power Programme and Community Energy Project are just some of the many concrete initiatives put in place by eLab in New York City.

A third example, MaRS Solutions Lab, describes itself in terms of its team's commitment to "tackling complex societal and economic challenges that require 
systems change" (https://www.marsdd.com/systems-change/mars-solutions-lab). Not unlike the two foregoing initiatives, it strives to assemble a mix of different individuals and organisations, with an emphasis on experimentation between stakeholders and citizens as well as new ventures. It aims to support the diffusion and scaling of new effective solutions. In terms of its toolbox of approaches, MaRS Solutions Lab is eclectic: it draws on social innovation, design thinking, change management and social movement theory, among other methodological strands. Its larger aspiration is to "build capacity for systems change" through advancing "policies and learning opportunities that support people and organizations to drive change (https://www.marsdd.com/). MaRS Solutions Lab is working on several specific challenges: Future of Health, Future of Food, Future of Work and Learning, and Future of Government, engaging with a variety of collaborators including government, foundations, corporations, NGOs, and many others. One tangible example of the labs' work is the creation of highly popular GovMaker - a network, community, events platform and telepresence series on social innovation for "civil servants and open government enthusiasts" (MaRS website, 2016). GovMaker has been working to change public servants' mindsets, encouraging collaboration on (potentially) high impact initiatives in Ontario and beyond.

Finally, Quartier Stuff in Luxembourg (http://quartierstuff.lu) is a community innovation lab aiming to empower the citizens, workers, visitors and other stakeholders in one district in Luxembourg city to shape the future of the area. The lab's aim is to "innovate ... to ensure long-term social cohesion and high quality of life." Quartier Stuff has kicked-off with a highly successful "shape your district" crowdsourcing campaign which brought in more than 1,250 suggestions on how to "co-create the district". As part of another initiative, teams of lab participants involving a range of stakeholders from different backgrounds (including young children) have been working on several co-defined challenges (in the fields such as "green", "mobility", "public space", "social life", "services" and "youth"), using a bespoke methodology based on open innovation and design thinking. Concrete innovative solutions for the district are presently entering the prototyping phase, yet the lab process has already been shown to contribute value to the life of the district by giving the stakeholders a way to not only express their opinions but to truly engage in hand-on co-design of concrete solutions to pressing challenges. This is reflected in the local and international interest in the initiative and numerous inquiries on how the process could be transferred to other areas and contexts.

These examples suggest, at the very least, that innovation labs set ambitious goals; seek ground-breaking solutions; convene "uncommon" collaborators; and frequently engage the wider public (through methods that include but are not limited to crowdsourcing or crowdfunding).

Yet, further conceptual and empirical work is needed if we are to confidently distinguish innovation labs from other innovation-based approaches and understand them as a coherent, distinctive organisational form. In the present article, our aim is to contribute to this task by examining how labs apply the principle of openness, and hence we devote less space to other significant but (for present purposes) less definitive aspects such as lab funding. 


\section{$3 \quad$ Literature review}

Three streams of literature are helpful when trying to place innovation labs in a broader innovation context: open innovation (3.1), open science (3.2) and open government (3.3). These will be reviewed here in some depth, followed by an overview of the scarce existing literature on the innovation labs themselves (3.4).

\subsection{Open innovation}

Open innovation describes the shift of corporate R\&D from an in-house discovery focus to external engagement (West et al., 2014, Chesbrough 2003), and recognises that innovative ideas can also come from outside the firm. Open innovation involves an external "crowd", and research suggests the exact way that this crowd will be used to generate innovation depends on two factors: the complexity of the innovation problem and the degree of expertise identifiability (Felin \& Zenger, 2014). Regarding problem complexity we can distinguish: i) simple problems, which involve a well-defined set of knowledge disciplines, are easily decomposed and their solution can be solicited by independent actors (Leiblein \& Macher, 2009), and ii) complex problems, which are ill-structured in terms of the involved disciplines, and their solution cannot be easily decomposed to independent actor level. Simple problems are best served by a trial-anderror search strategy for identifying the solution, where the crowd sequentially builds the solution, while complex problems require a theory-guided, often carefully staged search approach (Deutsch \& Baby, 2013), which first identifies relevant knowledge disciplines and then solicits crowd contributions. As for expertise identifiability, we can also distinguish two cases. In case that expertise is easy to identify then a centrallycoordinated crowd governance, where the firm appoints contribution roles to the crowd participants, is preferable. In the case that expertise is difficult to identify, then broadcasting the problem becomes a necessity in hope that those with valuable knowledge will reveal themselves (Jeppesen \& Lakhani, 2010).

Table 1 illustrates the most commonly used methods to evoke crowd contributions in the context of open innovation, transposing the above-mentioned two-by-two categorisation of Felin \& Zenger (2014) to the crowd-sourced domain. Reading from left to right and top to bottom, the first quadrant includes a micro-task based search approach, i.e. when the innovation task solicited by the crowd is simple, easily decomposable and expertise is evident, such as data categorization, curation, or enrichment (Kittur et al., 2008, Mohamed \& Deepak, 2013). When the task becomes complex, but still expertise is easy to identify (second quadrant) then centrallycoordinated expert-evoking search solutions are the best, for example through platforms like UpWork intended to hire expert crowd workers for complex tasks like knowledge synthesis or product design. The third quadrant describes the case of simple, straightforward tasks, which nevertheless entail a high degree of hidden knowledge. Idea contests, like Innovation Jam's discussion forums or Lego Mindstorms (Majchrzak \& Malhotra, 2013) belong to this category, relying on the crowd for novel ideas about a product and then improving these through a sequential search strategy. Crowdsourcing innovation brokers, such as Innocentive, Yet2, NineSigma, YourEncore, also belong to this quadrant, with the addition that they act as intermediaries between the firm and the crowd to address privacy concerns (Simula $\&$ 
Ahola, 2014). The fourth quadrant describes the case of complex problems entailing a high degree of hidden knowledge and it is the one posing the most challenges for organisations, possibly requiring emerging forms of openness. The reason is that, as also pointed out by Felin \& Zenger (2014), solving grand challenges necessitates collaboration and elaboration on the ideas of others, rather than simply gathering bursts of initial designs (Madsen et al., 2012). Multiple studies provide evidence that collaborative idea-creation by the crowd yields superior results in terms of innovation quality compared to autonomous individuals (Blohm et al., 2011; Madsen et al., 2012; Ye et al., 2012). In practice, however, implementing collaboration at crowd-scale is anything but easy: the competitive nature of crowdsourcing often makes people unwilling to share information with others (Adler \& Chen, 2011); idea evolution takes time and crowd participants generally do not stay involved for extended periods; and co-creativity requires familiarity while crowd teams consist of strangers (Majchrzak \& Malhotra 2013, Almirall et al. 2014). To make things worse, open innovation inherently involves a high degree of appropriation by organisations through capture of IP rights relating to innovations generated, yet such strong appropriation has been found to hamper collaboration (von Hippel, 2005, Murray and O'Mahony, 2007) and the motivation to participate (West et al., 2014, von Hippel, 2007). Due to these factors, the exact architectures, knowledge governance mechanisms and motivators that would optimally reconcile the need for IP protection as well as collaboration and motivation in the context of open innovation remain an ongoing subject of research. Methodological suggestions drawn from other successful innovation paradigms, like those adopted by Living Labs, could be examined to resolve such problems of practical applicability faced by open innovation scholars and practitioners, as discussed in the recent studies by Schuurman (2015) and Schuurman et al. (2016).

Table 1. Transposing Felin and Zenger's (2014) taxonomy to the crowd-sourcing context.

\begin{tabular}{lcc} 
& $\begin{array}{c}\text { Simple } \\
\text { (Trial \& error search) }\end{array}$ & $\begin{array}{c}\text { Complex } \\
\text { (Theory-guided search) }\end{array}$ \\
\hline $\begin{array}{l}\text { Low hidden knowledge } \\
\text { (Centralized selection) }\end{array}$ & $\begin{array}{c}(1) \\
\text { Micro-tasks }\end{array}$ & Expert crowd-based platforms \\
\hline $\begin{array}{l}\text { High hidden knowledge } \\
\text { (Self-selection) }\end{array}$ & $(3)$ & $(4)$ \\
& $\begin{array}{c}\text { Innovation brokers } \\
\text { Idea contests }\end{array}$ & Emerging forms of openness \\
\hline
\end{tabular}

Along with open innovation, two important axes to understand innovation labs include open science and open government. The similarity these share with open innovation is that all three appeal to an external crowd of contributors. They differ however in the importance and desirability they place on the rights of the participants over their contributed innovation (West et al., 2014): open innovation is firm-centric and naturally the firm is mostly interested in attaining the innovation rights (West and Lakhani, 2008), whereas open science and open government are more focused towards individual, consumer or societal welfare (von Hippel, 2007, von Hippel \& Krogh, G., 2006), and therefore more flexible in appropriating the contributors with rights, or even releasing the latter for the benefit of the greater public. 


\subsection{Open science}

Citizen science (Bonney et al., 2014) is a particularly relevant variety of open science involving amateur or nonprofessional scientists in collaboration through web or mobile technologies, with central coordination by an expert research team. Example projects include biodiversity monitoring (Kobori et al., 2015), community mapping (Ellul et al., 2012), astronomy like Galaxy Zoo (Masters et al., 2015) and volunteer computing projects like SETI at home (Korpela et al., 2015), or griderpublic ${ }^{2}$. Most of these projects are meant to feed into science projects run by professional scientists and not to involve citizen scientists in the final analysis or application of the science findings, though something called "extreme citizen science" (Haklay, 2013) strives to overcome this limit by opening up each stage to collaboration.

Another branch of citizen science, one that brings researchers and volunteers closer, is the newly introduced model of Massive Open Online Research (MOOR) (Vaish et al., 2015). MOOR projects, such as "The Aspiring Researcher Challenge", rely on the volunteers not only for speeding up the research work, but also for changing the volunteers' motivations to get more involvement and potentially better contributions. They offer volunteers the chance to collaborate with top scientists and to be involved in all stages of the research process, from idea conception, to data gathering, to analysis, and even to article writing and publications (see for example the paper by the Stanford Crowd Research Collective, 2015, with 61 crowd authors).

A third thread of open science aims at the massive collaboration of researchers, to promote better science practices. Illustrative are the recent studies by the Open Science Collaboration $(2012,2015)$, which through the coordinated community efforts of multiple scientists proved the low reproducibility of a considerable volume of psychology publications, initiated a general discussion questioning the standards of current science publications, generated the "Transparency and Openness Promotion (TOP) guidelines" ${ }^{4}$ for journals, and eventually highlighted the need for more data openness to ensure integrity. In another related effort, the Montreal Neurological Institute (MNI) recently announced its intention to examine whether forgoing patents and freeing up data can boost neuroscience research through duplication and crossvalidation by independent teams around the globe (Owens, 2016).

\subsection{Open government}

Open government (OG) refers to a set of government initiatives to promote transparency, empower citizens and use new technologies to strengthen governance (Huijboom \& Van den Broek, 2011; Robinson et al., 2009). The expected benefits can be political and social, such as improved policy-making processes, economic, like investor encouragement for innovation, and operational, such as data reuse and external validation. OG could also help explore tactics for reform in public organisation, including tactics that are necessary for overcoming the typical bureaucratic model of organising and allowing these organisations to more effectively cope with today's challenges (Thompson and Sanders, 1998). The OG concept has been strongly

\footnotetext{
${ }^{2}$ http://www.gridrepublic.org/

${ }^{3} \mathrm{https}$ //aspiringresearchers.soe.ucsc.edu/

${ }^{4}$ https://osf.io/ud578/
} 
encompassed at government level worldwide, including the US administration (Open Government Progress Report to the American People, 2009, the European Commission (European Commission, 2013), the governments of Canada (2016) and Australia (2010), local governments in China (Li, 2011), as well by the United Nations (United Nations Division for Public Administration and Development Management, 2013). At a public-private level, the Open Government Partnership (2016) initiative, providing open access to government data for a diverse set of private investors and public states, gathers 69 Member States. Finally, at local level, civic accelerators, such as Philadephia Change by Us and the New York Big Ideas (Almirall et al., 2014) are only indicative examples of the significant interest that open government attracts.

Despite its promising vision, open government initiatives often rely on the oversimplified belief that merely publishing government data will automatically yield the expected benefits, because the published data will be used by their intended recipients (Janssen et al., 2012), and that more open data will result in better democracy (Strathern, 2000). Accordingly, many current open government initiatives focus more on transparency in information dissemination rather than on citizen participation and collaboration (Hansson et al., 2015). Recent attempts to address these concerns and to achieve sustainable public engagement include the five engagement maturity levels by Lee and Kwak (2012), the ecosystem model for planning and designing OG programs by Dawes et al. (2016). Indeed, open government proponents are also moving more and more towards the "lab" model, which is illustrated greatly by the growing number of policy labs as an answer to policy-making. For instance, the Policy Lab, a specialist team based in the Cabinet Office of the UK government, "was set up within the context of Civil Service reform and in particular the Open Policy Making agenda. Funded by and working with government departments, the Policy Lab team brings new methods and tools to policy making and supports their practical application by civil servants." (Kimbell, 2015, p. 1)

\subsection{Innovation labs}

Besides the general openness literature described in the above three streams, some publications have already been released on innovation labs ${ }^{5}$ themselves. However, labs are still being mostly discussed by practitioners. For instance, The Change Lab Fieldbook (Hassan \& Bojer, 2005), the Reos Change Lab (ReosPartners, 2013), Social Innovation Lab Guide (Westley et al., 2014) or Unicef's (2014) “do-it-yourself” guide are all practical handbooks on how to run an innovation lab process. The Labcraft (Tiesinga \& Berkhout, 2014) elucidates "how labs cultivate change through innovation and collaboration". Bellefontaine (2012) introduces a noteworthy idea of innovation labs as bridging think-tanks and so-called do-tanks, and discusses the potential of labs for policymaking purposes. The Social Labs Revolution book (Hassan, 2014) discusses

\footnotetext{
5 "The early literature on new kinds of innovation labs has, as one would expect, an experimental character, which applies to the search for a settled, agreed upon label. While acknowledging the multiplicity of labels used and the evolving trends in this field, we have decided to use the term "innovation lab" to signify the types of labs examined in the present paper. We find this decision justified because (1) the vast majority of emerging labs would themselves recognise this label, making our paper accessible to this group of practitioners and founders; (2) paradigmatic labs such as the Finance Innovation Lab use this term; and because (3) innovation lab is sufficiently generic as a label to speak to diverse types of labs that share underlying shared features (as set out in section 5).
} 
the rise of the lab phenomenon in a narrative fashion without rigorous empirical or theoretical frameworks.

Social innovation funders have also been supporting innovation lab research. The Bridgespan Group and the Rockefeller Foundation have commissioned a series of lab surveys (see e.g. Bliss \& Sahni, 2014). Nesta's "i-teams" (Puttick et al. 2014) report uncovers how labs are used by local governments; "Innovation teams and labs" (Puttick, 2014) is a collection of lab practices from around the world; and a paper by Nesta's CEO (Mulgan, 2014) looks at the various social and public labs and describes some of the challenges they face - in particular, having to work both inside and outside established systems. The presence of innovation labs in the public sector is also studied by Tõnurist et al. (2015), who find that although labs have a significant potential to become change agents, their viability heavily depends on whether they can "evangelize" their results to other public sector units through informal networking.

Despite the unquestionable stir the labs have already caused among innovation practitioners and funders, the topic has gone largely unnoticed in academic innovation studies research. As confirmed by Google Scholar and EBSCO searches, besides a couple of working papers in progress (Gryszkiewicz et al., 2015, Gryszkiewicz et al., 2016; Toivonen et al., 2016) that approaches labs as collaborative innovation intermediaries, there are no peer-reviewed works on innovation labs available thus far. Our paper is an exploratory attempt to address this literature gap.

\section{$4 \quad$ Method}

The near-absence of existing research on innovation labs - a multi-dimensional phenomenon - demands an explorative approach, with qualitative methodology as a suitable choice for an initial investigation (Miles \& Huberman, 1994). Two main steps were taken by us to this end.

First, we performed a discourse analysis of the self-descriptions of 25+ labs from around the world, based on material published on their websites. The labs were chosen through theoretical sampling to cover a sufficiently wide range of sectors and geographies. We selected the websites that self-identified as an "innovation lab" or "social lab" - the list of investigated labs is presented in Appendix 1. Salient quotes from labs' self descriptions were analysed using sorting and clustering techniques (Miles \& Huberman, 1994).

Second, as suggested by Edmondson and MacManus (2007) for a nascent state of prior theory and a novel research field as ours, we have carried out semi-structured interviews with the founders and leaders of 12 labs (Charmaz, 2000; Eisenhardt, 1989; Legard et al., 2003). The list and duration of interviews is presented in Appendix 2 and the interview guide is included in Appendix 3. The interviews were complemented by secondary data analysis (including labs' annual reports, relevant information from their websites, publications, strategy documents, internal tools, external articles, activity on social media sites such as Twitter, Facebook etc). The data collection process as a whole has been iterative (Edmondson \& McManus, 2007, Yin, 2009). The interviews were transcribed by professional transcription agency. Data analysis was supported by NVivo-facilitated iterative coding process (Miles \& Huberman, 1994), focusing on 
each lab's self-description, innovation process and evidence of openness.

\section{$5 \quad$ Results: Common characteristics of innovation labs}

In this section, we introduce key findings from our original interviews and labs' selfdescriptions (collected from their websites). We group these findings according to each shared lab characteristic that emerges from the data.

\subsection{Open-ended innovation themes that are pre-designated}

While innovation labs seek contributions from a variety of sources, they designate the core theme(s) of innovation in a largely top-down manner, whether related to young people's mental health, finance or park enhancement. In many cases this theme emanates from the founders' personal experiences, as in the case of The Comms Lab that strives to transform advertising from a system "propagating the myth of endless growth" to a sustainability catalyst. Founders are often linked to larger organisations in the private, public or civic sectors, or have worked extensively in a particular field (as the co-founder of The Comms Lab has done in advertising), which influences the choice of themes. In the case of larger labs run and/or funded by Nesta (including the Innovation Growth Lab that develops Randomised Controlled Trials as a methodology for tracing social impact) the origin of core themes is more opaque, to the extent that the programme coordinators we interviewed were unaware of how these come about (though they did agree that department heads and the CEO are in an influential role). Funders can also set core themes, as in the case of InnovationLabs that was founded at the initiative of three funders (Paul Hamlyn Foundation, Comic Relief and Nominet Trust) keen to generate digital solutions to youth mental health problems. All of this reflects the fact that, while a degree of collective decision-making may be present, labs can be viewed as instruments or vehicles for the furthering of their founders' (and/or funders') visions.

This said, labs intentionally leave room for the further specification of the focal problem, as their themes are far from narrowly defined (e.g., "revolutionising the energy sector", as in the case of eLab). This owes to the assumption that the problems labs tackle are highly complex and often ambiguous; it thus makes sense for them to start with open-ended themes rather than precise (but wrong or simplistic) definitions. In this way, labs allow for co-definition and co-creation without going as far as starting with an entirely open slate or sourcing their key themes through a participatory process of some kind. (Indeed, it would be challenging to imagine how innovation labs could function without any pre-designation of themes whatsoever; in this sense the "topdown" elements of labs seem to some extent necessary).

\subsection{Open or semi-open call for heterogeneous participants (including stakeholders)}

Rather than appoint an internal or otherwise well-defined group of experts at the outset, innovation labs typically broadcast an open or semi-open call for participants. Such calls function through a symbolic logic whereby key messages broadcast by a lab trigger what is essentially a process of self-selection (rather than a formal lab-controlled application or recruitment process, though such processes may be utilised to a small 
extent when launching sub-programmes such as lab fellowships or related startup incubation programmes).

While core teams that initiate labs and enact their basic architectures may or may not be diverse, as a rule labs seek to engage a wide range of heterogeneous participants from across different industries, professions, and cultures, something the open call approach can support. Thus, Dan Hill, the then-chief design officer of the Future Cities Catapult (that runs several lab-projects, including Sensing Cities) stated in 2015 that:

To make the cities we really want to live in requires all these elements to begin working together: architects with coders; city planners with ethnographers; engineers with interaction designers. That's always been a core belief of Future Cities Catapult [...]. (Hill, 2015).

The founders of the Finance Innovation Lab describe the process that led to the birth of their lab as follows:

ICAEW [one of FIL's host organisations] invited their stakeholders; accountants, financiers, the business community. WWF [another FIL host organisation] invited theirs; environmental activists, civil society and the responsible investment community. Despite the bizarre spectacle, we had brought together people who don't normally meet each other, to talk about things they cared deeply about and the energy generated in that room showed us it was a conversation that wanted to continue [emphasis added] (FIL, 2016).

After this first meeting between "uncommon partners", FIL openly called for a wider range of participants to join its many events and asked them to self-organise into effective teams according to shared interests and goals.

This aspiration for breadth is motivated by the assumption that diverse lab participants can construct a more complete "view" of a given problem or system, including an understanding of their consequences to key stakeholder groups. As importantly, diversity is seen as a potential stimulant of experimentation and innovation, since a wider range of ideas and perspectives can enable a greater variety of creative recombinations.

Finally, open or semi-open convening is favoured due to the strong participatory orientation and values of labs. ${ }^{6}$ For instance, InnovationLabs engaged not only doctors and coders, but regular young people to inform and co-develop apps that could support youth mental health in novel ways. It reached out to prospective participants in a semiopen fashion through its networks and its partners. London-based labs generally contend that those whose lives are being shaped by a given system should be involved in reshaping and reconfiguring it. In the words of the Comms Lab director:

\footnotetext{
${ }^{6}$ We are aware of the existence of more exclusive labs such as the Global Knowledge Initiative that works to reduce food waste through engaging CEOs (Bliss \& Sahni, 2014; also see Hassan, 2014). While further systematic research is needed, our present view is that such "executive labs" should be distinguished from the far more participatory labs that characterise our sample.
} 
[A lab is] a space [...] for people who represent a system and [...] who are influenced by a system to come together and - with the similar intention of wanting to change things - to come together and co-create [...].

Thus, many labs stress openness due to their commitment to stakeholder groups, but also plausibly due to key challenges inherent in the implementation and management of open innovation (in particular, the challenges of coping in situations where knowledge is largely hidden and the core problem is complex, as elucidated in our literature review). We will return to this point in our concluding section.

\subsection{Open collaboration across boundaries through shared formats and culture}

In the above, we have shown how labs strive to convene a heterogeneous group of "uncommon partners" based on the perceived benefits of such an approach. But given that working together across established boundaries (e.g. organisational and disciplinary boundaries) is notoriously difficult, what makes continued collaborative activities possible between lab participants?

Clearly, lab founders and core staff play a vital role in catalysing collaboration through acts of intermediation. They facilitate interaction at lab events and introduce participants to one another through various means, serving as collaborative brokers. As labs work in a (semi-) open fashion and engage a range of diverse participants who do not share the same assumptions, collaboration is maintained through two further elements: interaction formats and collaborative culture. The former range from games and small group discussion to rapid prototyping and systems mapping exercises. These frameworks can support constructive and creative communication across differences and organisational boundaries by giving direction and structure to discussions that might otherwise be challenging to conduct (or produce no tangible outputs). For instance, the leader of the mHabitat Digital Discovery Lab explains that, after her lab gets approached by a clinical service (that is interested in new digital tools) and sets up an initial hypothesis, it proceeds to:

$$
\begin{aligned}
& \text {...run what we call a Discovery Day, but it's a bit like a hack day where } \\
& \text { we get patients, clinicians, academics, developers, designers, all } \\
& \text { together and we get them into teams answering the same question, and } \\
& \text { then we have a 'show and tell' where they share what they found, } \\
& \text { developed during the day [...]. }
\end{aligned}
$$

The Discovery Day forms an integral part of the lab's rapid prototyping approach, and the formats it incorporates have proven effective for getting diverse participants to cocreate together.

Labs furthermore build a collaborative culture through less obvious ways, including by emphasising collaborative, egalitarian relationships over hierarchical or commercial roles (such as "client", "consultant" or "user"):

We work on a range of fairly long term projects with a range of partners where we don't see the relationship that we build with them as one of being consultants, but one of real collaborative partner in exploring certain things. Now, that is really important to us [...] (co-founder, Civic Systems Lab). 
Also, many labs frequently remind participants that they share the same values and work on complementary parts of the larger "puzzle" of systemic change in a given area. In the case of FIL, there is moreover a strong emphasis on informality and authenticity whereby participants are called to interact as "genuine whole-person individuals" first, rather than as professionals or representatives of formal organisations. The lab believes this intimate relational orientation helps increase trust and friendship between diverse participants who may never have met before.

Innovation lab core teams are usually themselves active in entering into partnerships with various external organisations, as they realise that labs have limited capabilities alone. This is why iLabs claims to be based on "cross-sector collaborations that bring people together", the eLab to be a "group [that] focuses on collaborative innovation" and Nesta's Innovation Growth Lab advocates for "global collaboration". Such a strong focus on partnership and collaboration raises the interesting question - that lies beyond the present account - of whether and how labs are shaped by the multiple institutional logics they become exposed to.

\subsection{Continued open involvement throughout the innovation process}

Labs not only convene heterogeneous participants and facilitate long-term collaboration - they strive to maintain an open approach throughout the innovation process. This stands in stark contrast to classic open innovation approaches that typically solicit a range of inputs at the ideation stage but revert to smaller (in-house) expert teams in subsequent phases, finally appropriating the resulting services and products as far as possible through intellectual property rights. Innovation lab participants, our sample suggests, are expected to co-create ideas and bring them towards implementation through concrete prototyping activities. In their own words, labs are "application-oriented" (InnovationLab) and "dedicated to the development of real solutions" (Civic Innovation Lab). Such hands-on collaboration is made possible by relatively close relations between participants - contrasting with anonymous online crowds or participants in one-off hackathons - and indeed the autonomous nature of innovation labs means there is usually no parent organisation hungry to appropriate the solutions generated (though the subsequent copying of attractive, successful ideas is likely to be common). Owing partly to the very recent emergence of the innovation labs phenomenon, most labs have not necessarily accumulated a significant amount of experience vis-a-vis the implementation of co-created ideas, but the generation of practical solutions in an open fashion is nevertheless fundamental to their ethos.

\subsection{Solving large-scale innovation challenges in the context of open systems}

Labs typically seek out-of-the-box solutions to large "systemic" challenges with serious implications for the future of our societies. In doing so they strive to apply creative multi-level approaches that span the boundaries of different sectors and organisations. Examples include: exploring and building different civic systems (Civic Systems Lab), changing the financial system by devising alternative business models that bypass large banks and rely on crowdfunding to direct investment into green energy (Finance Innovation Lab) and working towards solving "large health, safety and development problems" (iLabs) in multiple parts of the world simultaneously. Labs thus strive to make amorphous socio-technical systems seem malleable and accessible to hands-on 
intervention; in other words, they "open up" systems for reconfiguration and realignment More fundamentally, they deal with open rather than closed systems, hence their use of terminology such as "wicked", "complex" or "systemic" problems. This is a vital point that helps explain how labs differ with classic R\&D labs and product innovation approaches that often operate under a "closed system" assumption rather than dealing with the ambiguity and porousness of domain boundaries (and the full complexity of socio-technical challenges).

\subsection{Open time horizons (long-termism)}

Most of the innovation labs in our sample adopt an open-ended, broad-minded approach to their work as opposed to emphasising proximate deadlines or performance targets. This is reflected in the common use of evocative, imprecise terminology by labs when describing their goals (e.g., "discovering the future", as in the case of Nordstrom Labs; "exploring" and "building" better civic systems in the case of the Civic Systems Lab; or more generally, "systemic change"). Such a view beyond immediate results creates space for expansive thinking across longer time scales. This orientation is embodied in the frequent use of foresight activities such as horizon scanning, foresight scenarios, strategic planning or emergent signal analysis (sLab), as well as in efforts to map broader systems, from finance to energy and material production (that labs would admit can take years or decades to transform). Their long-termism allows labs to open up niche spaces (Schot \& Geels, 2008) where new visions and innovations can be gradually incubated and developed. Here, much depends on the willingness of the founding individuals and organisations to commit a significant period of time sometimes a decade or more - to realising the vision of their lab. In the case of FIL, the founding members (though not necessarily the two host organisations) agreed at the outset to commit the next 15 years of their lives to advancing the lab's mission together. ${ }^{7}$ Since the majority of modern innovation labs - certainly including all labs in our sample - have been established in the past decade, it is too early to assess their actual longevity ${ }^{8}$, and to evaluate their long-term impacts, though this will increasingly become possible in the next few years.

Other innovation lab characteristics. In the above sub-sections (5.1 through 5.6) we have reported innovation lab characteristics that, in light of our data, seem central to the labs included in our sample and elucidate their approach to openness in the innovation process. However, this has by no means provided an exhaustive analysis of innovation labs and it is clear that they possess many other features and dynamics of interest. We suggest that future research interrogate the following lab characteristics: pursuit of disruptive, "breakthrough" solutions rather than incremental innovation (e.g., inCompass Human-Centered Innovation Lab); autonomous or semi-autonomous organisational position (e.g. Nordstrom Labs) where labs are able to span

\footnotetext{
${ }^{7}$ Jennifer Morgan's presentation at the Global Systemic Change Roundtable (Academics Stand Against Poverty), Oxford, 3 March 2016.

${ }^{8}$ Our sample being exploratory, it includes one lab with an explicitly time-limited format: the InnovationLabs (2011-2013) intended to generate a small number of ideas that could be developed through grant funding into products to support young people's mental health. We are also cognisant that some labs, including the RSA Great Recovery programme that has focused on advancing the circular economy model, are designed to come to an end when their funding period concludes, though additional funding may allow for a longer life-span even in these types of cases.
} 
organisational boundaries, allowing for diverse collaborative partnerships and increasing the freedom to experiment (e.g. Quartier Stuff); rich innovation toolboxes instead of a preoccupation with a single approach to innovation, ranging from design thinking and open innovation (sLab, Quartier Stuff) to RCTs (Nesta's Innovation Growth Lab) and Human Centred Design (inCompass). While none of the characteristics listed here (and in 5.1-5.6) are unique to innovation labs as such, it is their combination that makes labs a genuinely novel phenomenon - one with potent lessons for innovation management. The following section will clarify more sharply how innovation labs differ from other salient organisational forms and approaches that analysts sometimes associate them with (in the absence of prior clear definitions in the academic and practitioner literatures).

\section{What is not an innovation lab?}

While ostensibly similar to many other organisational types that utilise openness in processes of innovation, our research shows that a combination of certain critical differences makes innovation labs a distinct organisational form. In order to sharply elucidate these distinctions, in this section we build on the analysis thus far and take a look at what is not an innovation lab.

Innovation hub. Hubs (e.g. Impact Hub) serve entrepreneurial individuals by giving them access to a vibrant community, affordable workspace and valuable networks. While innovation labs share many features with hubs - like the belief that innovation benefits from the experimental mix of diverse cognitive resources (Friederici \& Toivonen, 2015; Toivonen, 2016) - they differ with the latter in at least four respects. First, labs tend to serve a different clientele: members of established organisations rather than, or along with entrepreneurial individuals. Second, they essentially use topdown governance processes; where hubs seek to gently "enable" innovation (Gryszkiewicz \& Friederici 2014), labs strive to more firmly steer it. Third, innovation labs set the parameters of innovation clearly around specific themes (e.g. sustainable finance or responsible advertising), as opposed to hubs' identification only with relatively broad domains such as ICT (Gathege \& Moraa, 2013) or social impact (Bachmann, 2014). Finally, compared to hubs, labs are more directly linked to the agendas of larger corporate, public or civic organisations. For instance, the Finance Innovation Lab was originally co-convened by WWF-UK (World Wide Fund for Nature) and ICAEW (Institute of Chartered Accountants in England and Wales), though it subsequently became independent.

Corporate R\&D lab. Corporate R\&D labs (e.g. Intel, Lowe, Tesco, Walmart) are inhouse departments with dedicated physical "facilities for encouraging creative behaviours and supporting innovative projects" (Lewis \& Moultrie, 2005). An example, Lowe's laboratory (LIL, http://www.lowesinnovationlabs.com/), aims to be a disruptive innovation leader in the retail industry. While it relies on a team of uncommon partners to develop solutions such as the Holoroom (an augmented reality science fiction-inspired simulator for home improvement) and Autonomous Retail Service Robot (challenging the future of shopping experience), these innovations still fall under the auspices of corporate Lowe's top management. Innovation labs, by contrast, are stand-alone structures, often with a purposefully maintained "startup 
culture", and much more open to the participation of external actors. Also, their teams are diverse compared to those of typical corporate R\&D labs. Moreover, corporatesector "innovative spaces" (Magadley \& Birdi, 2009; Oksanen \& Ståhle, 2013) are purpose-built physical environments whereas innovation labs, as proposed in this paper, are a broader concept, often with no designated physical space at all (e.g. as is in case of the The Comms Lab).

Community of practice (CoP). Communities of practice ("groups of people informally bound together by shared expertise and passion for a joint enterprise"; Wenger \& Snyder, 2000: 139), are more homogenous than labs, usually representing a given profession or industry. Their focus is on "support for members interacting with each other, sharing knowledge, and building a sense of belonging within networks/teams/groups" (Li et al. 2009), whereas labs focus on seeking innovative solutions through engaging a wide group of stakeholders, with experts involved only part of the time. Moreover, CoPs tend to follow a single methodology ("learning while doing") rather than a mix of tools to stimulate innovation, as is the case in labs. Finally, CoPs are reported to innovate incrementally, embracing concepts such as continuous improvement or kaizen, whereas labs strive to make radical leaps through their innovation efforts.

Living lab. Living labs - initially defined as "real-world contexts in which users were given the opportunity to use state-of-the art technology" (Folstad, 2008, p. 49) - are now typically viewed as constituting "co-creation and appropriation of innovations by users, often in a (online or offline) community setting, and also involving business stakeholders" (Ballon \& Schuurman, 2015). While living labs are closely related to innovation labs, there are some aspects that make them different. First of all, living Labs actually label themselves clearly as Living Labs and they often form part of larger networks (see the network organisation ENoLL), while innovation labs rarely do so. Another core difference with the innovation lab is that the living lab concept is fuelled mostly by the individual user experimentation and testing, or, as argued by Leminen et al.'s (2012) typology, living labs are either predominantly utilizer-driven, or enablerdriven, or provider-driven or user-driven. Either way, the user is always involved as key stakeholder in a living lab, which is not necessarily the case for innovation labs. The aspiration of an innovation lab, on the other hand, is to always involve a very broad representation of a variety of actors, inviting more stakeholder groups from beyond the user circle to contribute. For instance, the eLab participants represent all aspects of the electricity system: resource providers, customers, investors, regulators, grid operators, utilities representatives, advocates and experts. Secondly, living labs aim at operating within 'real-life environments' (Leminen et al., 2012) or a 'real-life context', which is not necessarily the case for innovation labs that often innovate 'out of context'. In fact, pulling innovative participants out from their usual working environment is precisely what often makes innovation labs so powerful in terms of their creative potential.

Innovation network. The purpose of various innovation networks (whether professional networks, associations or business networks) is to bring dispersed actors together to share information. These 'loosely coupled' systems (Freeman, 1991) tend to focus on the 'network paradigm' (Cooke \& Morgan, 1993) or 'networking' itself as their core activity. Therefore, they would put most their efforts into creating conditions for reciprocity, trust, learning, partnership and decentralism (Cooke, 1996) to 
potentially affect their innovation performance and productivity (Pittaway et al., 2004) in the long run. By contrast, innovation labs typically define a clear purpose of the lab; invite participants; run projects and oversee collaboration. Hence an innovation lab cannot be reduced to a loosely coupled innovation network, even though it does actively exploit networking in its operations. Rather, it could be perceived as 'network orchestrator' (Dhanaraj \& Parkhe, 2006).

Innovation task-force. Task forces are best known for being applied by organisations such as NASA or local governments (e.g. New Orleans Innovation Delivery Task Force) for the creative resolution of crisis situations (such as recent oil spills). What they share with innovation labs is that they are at the lookout for breakthrough solutions. Yet, while innovation task forces are typically reactive, the labs proactively search for new solutions, focusing on future challenges rather than on ad hoc issues of the present. As The Comms Lab puts it: "We're doing this because we care about the future of the world and we care about the future of our industry" (The Comms Lab, 2016).

\section{Innovation lab: towards a definition}

Based on sections 5 and 6 , we are now in a position to provisionally define "innovation lab" as follows:

An innovation lab is a semi-autonomous organisation that engages diverse participants - on a long-term basis - in open collaboration for the purpose of creating, elaborating, and prototyping radical solutions to open-ended systemic challenges.

It is clear furthermore that in order to function, labs require access to suitable interactive spaces (physical as well as virtual) and mastery of co-creation methods that can stimulate and channel collective creativity. Put more succinctly, labs can be viewed as systemic or societal - rather than merely intra-organisational - vehicles for transformative change.

\section{Discussion and conclusions}

In this article, we have reported the results of an exploratory survey of innovation labs that has allowed us to shed light on their key features - as well as their differences - visa-vis other innovation-focused organisational types. In light of these, we are now able to return to a key question set up in our introduction (and further contextualised in the literature review presented in section 3 ): how exactly does the way in which labs apply "openness" in the course of their work diverge with notions of openness given in the innovation management literature, as well as the open science and open government literatures?

First, to address innovation management research, innovation labs clearly do open up the front-end of their innovation process to many participants, suggesting that open innovation (Chesbrough et al, 2006) is indeed integral to their nature. Yet, the notions of inbound and outbound innovation (Chesbrough et al, 2006) fail to adequately capture 
the more complex, multi-directional and networked nature of how innovation in labs takes place. Our data suggests that, in the case of labs, it is the breadth of stakeholders, combined with rich innovation toolboxes (or formats), that create an environment conducive to co-creation (Prahalad \& Ramaswamy, 2013). This clearly contrasts with the conventional notion of open innovation. Moreover, while Chesbrough's paradigm has often been criticised for opening up merely the front-end of the innovation process, we suggest that labs would rather apply methods such as crowdsourcing (Howe, 2006), design thinking (Rowe, 1991), service design (Shostack, 1982) or user innovation (Von Hippel, 2009) to keep the whole innovation process open. Also, unlike typical open innovation initiatives, labs do not place too much focus on the contributors asserting the IP of their inputs. As shown in the related literature this reduced stress on IP can lead to increased collaboration and increased motivation: two elements that are absolutely necessary for solving grand challenges (fitting in the fourth quadrant of Table 1 in section 3), and two elements that current open innovation initiatives are missing. Finally, we theorise that labs' intensive efforts to create a collaborative culture help overcome some of the fundamental limits of open innovation and crowd-sourcing: long-term engagement and lack of familiarity (incl. mutual trust) with other participants often referred to in the literature (Majchrzak \& Malhotra 2013, Almirall et al. 2014).

Second and in relation to open science (David, 1998), while some labs draw on approaches also seen in this field, including the pursuit of public knowledge and value, they go beyond this paradigm by moving from knowledge-generation to practical implementation by developing concrete solutions. Also, unlike most open science initiatives (except for the very new MOOR effort), innovation labs involve the participants in the whole innovation process, not just data collection to feed the actual research.

Third, open government (Janssen et al., 2012) only partly overlaps with the labs' notion of openness. Some innovation labs indeed are set up as governments' instruments (Puttick et al., 2014), but many others are driven by non-governmental or corporate actors. Also, while governments might invite open consultations, they would typically still be bound by bureaucratic and policy-making processes to actually implement the collectively developed solutions. Innovation labs, on the other hand, thanks to their more independent nature, have more leeway to leverage the gathered ideas and actually create real innovations.

Fourth and more generally, if we define "openness" in terms of inclusiveness and transparency (Whittington et al., 2011), innovation labs would typically go further on at least one of these dimensions compared to typical open innovation, open science and open government initiatives. This is possibly shaped by the very nature of the "systemic" problems that labs aim to deal with, which requires an approach that is far broader and more participatory.

In summary, openness in labs partly overlaps with but significantly transcends each of the above paradigms (open innovation, open science, open government). The way in which labs combine various facets of openness - adding up possibly to a qualitatively different approach to openness in innovation - merits further research, as discussed in the following section.

On a critical note, while we do find that labs possess significant potential in terms of catalysing radical innovation, it is necessary to remain alert to differences between 
openness on the level of discourse and openness in practice: for instance, even if lab participants appear to be "diverse", it is important to cast light on how they were selected and who got to do the selecting. The need for labs to serve the agendas of powerful actors is likely to militate against thoroughly serendipitous (self-)selection and team formation, as this may appear too time-consuming or random. If true, openness exists in a somewhat limited form here, with implications to the innovative processes that labs facilitate. There are also other potential openness dis-benefits associated with what can be an overwhelming coordination task. Finally, the expectation of radicalness raises distinct dilemmas: for instance, which degree of openness will simultaneously increase the chances of finding a breakthrough solution and allow for a fair distribution of the intellectual property created?

In conclusion, innovation labs offer a prime setting for the study of different aspects and limitations of openness. Further research efforts in this fascinating field of inquiry are strongly encouraged.

\section{Research implications, limitations and key questions for future research}

Our paper has several practical implications. Policy-makers and managers are increasingly looking for new ways to drive radical innovation and collaborative open approaches have been increasingly popular across a variety of policy domains and industry sectors. Despite their potential limitations and longer time to required to establish their true value, innovation labs can be an interesting option to consider by both types of actors. The rapidly rising profile of innovation labs, supported by the conclusions of this paper, suggests that labs have the potential to offer offer novel benefits for supporting radical innovation where open approaches are desired. At the moment, innovation labs have been under-used by both policy-makers (typically preferring public consultations or advisory boards) and corporations (typically using more classic open innovation approaches). This paper can inspire both groups to experiment with this novel form where current approaches are not sufficiently collaborative, do not allow for enough hands-on stakeholder involvement, or are not sufficiently geared towards radical solutions for grand challenges. For the more theoretically-inclined readers of this journal, our paper serves as one of the very first attempts to conceptualise what an innovation lab actually is and how it claims to leverage innovation for the purpose of radical innovation. This, of course, is a necessary starting point for future research endeavours which should take a much deeper look into innovation labs' actual practices, impacts, and also (emerging) typologies. Future research avenues are described further below in this section.

Admittedly, the most important limitation of this exploratory paper is the fact that we have relied on labs' self definitions and interviews, along with some practitioner publications. Indeed, thus far we have not had the chance to contrast these with longterm empirical observations of labs' organisational practices. Organisational ethnography (Neyland, 2007), structured observation techniques (Mintzberg, 1970; Martinko and Gardner, 1985) and practice-based approaches (Feldman \& Orlikowski, 2011) will allow future research projects to set labs' self-discourses in the context of their actual practices. We also acknowledge the geographic limitations of our research 
- we focused primarily on London in our empirical interviews, based on the recognition that it is a hotbed and leading centre for the lab phenomenon that disproportionately shapes innovation labs elsewhere. The far more global selection of labs for website analysis has served to counteract this limitation. Moreover, keeping in mind the exploratory nature of our paper trying to make sense of a fast-evolving field of labs that is in the middle of experimentation, our aim was to provide qualitative depth on selfdefinitions and central lab strategies instead of a global mapping of labs. We also wanted to generate a working definition that can bring further precision to future studies. This is a necessary step on the way towards papers that are able to respond to some of the expectations that could not, for reasons stated, be met by our paper, considering the stage of research at present.

Several promising research questions emerge that could help validate our first observations and further explore the fascinating phenomenon of innovation labs. Various theoretical perspectives could prove useful in answering these questions, and different research methods could prove salient for such investigations. A summary of future research avenues is presented in Table 2 below.

Table 2. Promising research directions and guidelines for future work in innovation labs topic

\begin{tabular}{|c|c|c|}
\hline Research questions & $\begin{array}{l}\text { Potentially useful theoretical } \\
\text { perspectives }\end{array}$ & $\begin{array}{l}\text { Exemplary research } \\
\text { methods }\end{array}$ \\
\hline $\begin{array}{l}\text { What are the collaborative innovation practices } \\
\text { and 'toolboxes' applied by innovation labs? What } \\
\text { are the best ways for the innovation labs to } \\
\text { organise themselves in that respect? }\end{array}$ & $\begin{array}{l}\text { Organisational practice, Open } \\
\text { innovation, Collaboration }\end{array}$ & $\begin{array}{l}\text { Case studies, } \\
\text { Observation, Interviews }\end{array}$ \\
\hline $\begin{array}{l}\text { What are the limitations of openness in innovation } \\
\text { labs? }\end{array}$ & $\begin{array}{l}\text { Open innovation, Resource-based } \\
\text { view, (intellectual assets) }\end{array}$ & $\begin{array}{l}\text { Case studies, } \\
\text { Observation, Interviews }\end{array}$ \\
\hline $\begin{array}{l}\text { Do labs successfully produce new (diverse) teams } \\
\text { that then become the central innovation agents } \\
\text { advancing particular projects? }\end{array}$ & $\begin{array}{l}\text { Team creativity, Recombinant } \\
\text { innovation, Entrepreneurial teams }\end{array}$ & $\begin{array}{l}\text { Interviews, Observation, } \\
\text { Network mapping }\end{array}$ \\
\hline $\begin{array}{l}\text { How can innovation labs benefit from new } \\
\text { collaboration technologies? How can new } \\
\text { collaboration technologies be transformed to help } \\
\text { radical innovation in labs? }\end{array}$ & $\begin{array}{l}\text { Collective intelligence, } \\
\text { Collaboration, Creativity }\end{array}$ & Experiments \\
\hline $\begin{array}{l}\text { What are the key organisational capabilities of } \\
\text { successful innovation labs? }\end{array}$ & $\begin{array}{l}\text { Resource-based view, Capabilities } \\
\text { theory }\end{array}$ & $\begin{array}{l}\text { Case studies, Interviews, } \\
\text { Observation }\end{array}$ \\
\hline $\begin{array}{l}\text { What are the actual predominant 'units of } \\
\text { innovation' at labs? (individuals, teams, labs } \\
\text { themselves)? }\end{array}$ & $\begin{array}{l}\text { Organisational practice, } \\
\text { Capabilities theory }\end{array}$ & Multi-level analysis \\
\hline $\begin{array}{l}\text { What innovation labs typologies might be } \\
\text { constructed to facilitate research? }\end{array}$ & Innovation labs literature & $\begin{array}{l}\text { Case studies, Interviews, } \\
\text { Observation, Coding, } \\
\text { Patterns matching }\end{array}$ \\
\hline $\begin{array}{l}\text { For which industries/themes are innovation labs } \\
\text { the most relevant? }\end{array}$ & Innovation labs typology & $\begin{array}{l}\text { Case studies, Interviews, } \\
\text { Observation, Coding, } \\
\text { Patterns matching }\end{array}$ \\
\hline
\end{tabular}




\section{References}

Adler, P., Chen, C. (2011). Combining creativity and control: understanding individual motivation in large-scale collaborative creativity. Accounting, Organizations and Society, 36, 63-85.

Almirall, E., Lee, M., \& Majchrzak, A. (2014). Open innovation requires integrated competition-community ecosystems: Lessons learned from civic open innovation, Business Horizons, 57 (3), 391-400.

Australian Government (2010). Declaration of Open Government. (2010). Web site of the Australian Government Department of Finance. Retrieved April 02, 2016, from http:/www.finance.gov.au/blog/2010/07/16/declaration-open-government

Bachmann, M. (2014). How the Hub Found Its Center. Stanford Social Innovation Review (Winter). https://ssir.org/articles/entry/how the hub found its center

Ballon, P., \& Schuurman, D. (2015). Living labs: concepts, tools and cases, info, 17(4).

Bellefontaine, T. (2012). Innovation Labs: Bridging Think Tanks and Do Tanks, Policy Horizons Canada.

Bliss, A., \& Sahni, N. (2014). Four Social-Change Results that Innovation Labs Deliver. Retrieved from http://ssir.org/articles/entry/four social change results that innovation labs de liver

Blohm, I., Bretschneider, U., Leimeister, J., \& Krcmar, H. (2011). Does collaboration among participants lead to better ideas in IT-based idea competitions? An empirical investigation. International Journal of Networking and Virtual Organizations, 9 (2), 106-122.

Bonney, R, Shirk, J. L., Phillips, T. B., Wiggins, A., Ballard,H. Z. , Miller-Rushing, A. J., \& Parrish, J. K. (2014). Next steps for citizen science. Science 343: 1436-1437

Charmaz, K. (2000) Constructivist and objectivist grounded theory. Handbook of qualitative research, 2, 509-535.

Chesbrough, H. (2003) Open Innovation: The New Imperative for Creating and Profiting from Technology. Harvard Business School Press, Boston

Chesbrough, H., Vanhaverbeke, W., \& West, J. (2006). Open Innovation: Researching a New Paradigm.

Cooke, P., \& Morgan, K. (1993). The network paradigm: new departures in corporate and regional development. Environment and planning D: Society and space, 11(5), 543-564.

Cooke, P. (1996). The new wave of regional innovation networks: analysis, characteristics and strategy. Small Business Economics, 8(2), 159-171.

David, P. A. (1998). Common agency contracting and the emergence of" open science" institutions. American Economic Review, 15-21.

Dawes, S. S., Vidiasova, L., \& Parkhimovich, O. (2016) Planning and designing open government data programs: An ecosystem approach, Government Information Quarterly, 33 (1), 15-27.

Deutsch, C., \& Baby Y., (2013), Solving complex problems: The Seeking Solutions 
approach, Journal of Innovation Management, 1(1), 11-16

Dhanaraj, C., \& Parkhe, A. (2006). Orchestrating innovation networks. Academy of management review, 31(3), 659-669.

Edmondson, A. C., \& McManus, S. E. (2007). Methodological fit in management field research. Academy of Management Review, 32(4), 1246-1264.

Eisenhardt, K. M. (1989). Building theories from case study research. Academy of Management Review, 14(4), 532-550.

Ellul, C., Francis, L., \& Haklay, M. (2012). Engaging with local communities: A review of three years of community mapping. Urban and Regional Data Management, UDMS Annual 2011 - Proceedings of the Urban Data Management Society Symposium, 165 - 177

European Commission. (2013). A vision for public services. Retrieved April 02, 2016, from

http://ec.europa.eu/information_society/newsroom/cf/dae/document.cfm?doc_id $=3179$

Feldman, M. S., \& Orlikowski, W. J. (2011). Theorizing practice and practicing theory. Organization Science, 22(5), 1240-1253.

Felin, T., \& Zenger, T. R. (2014) Closed or open innovation? Problem solving and the governance choice, Research Policy, 43 (5), 914-925.

Finance Innovation Lab (2016) Our story. The Finance Innovation Lab website, accessed on 5 April 2016. URL: http://financeinnovationlab.org/about-us/ourstory/

Freeman, C. (1991). Networks of innovators: a synthesis of research issues. Research policy, 20(5), 499-514.

Følstad, A. (2008). Towards a living lab for the development of online community services. The Electronic Journal for Virtual Organizations and Networks, 10, 4758.

Gathege, D., \& Moraa, H. (2013). Draft Report on Comparative Study on Innovation Hubs Across Africa, iHub Research

Government of Canada. (2016). Canada's action plan on open government. Retrieved April 02, 2016, from http://data.gc.ca/eng/canadas-action-plan-open-government

Gryszkiewicz, L., Friederici, N. (2014). Learning from innovation hubs: fluidity, serendipity and community combined. InnovationManagagement.se, (December 2014). Retrieved from

http://www.innovationmanagement.se/2014/12/15/learning-from-innovationhubs-fluidity-serendipity-and-community-combined/

Gryszkiewicz, L., Edwards, M., Friederici, N., Jimenez, M., \& Mention, A.-L. (2016). Emergent collaborative innovation intermediaries: innovation hubs vs. innovation labs. ISPIM, 19-22 June 2016, Porto.

Gryszkiewicz, L., Rousseau, A., \& Mention, A.-L. (2015). New frontiers of collaboration: innovation labs. Paper presented at the ISPIM, 14-17 June 2015, Budapest.

Haklay, M.. (2013). Citizen Science and Volunteered Geographic Information - 
overview and typology of participation, In Sui, D.Z., Elwood, S. and M.F. Goodchild (eds.), Crowdsourcing Geographic Knowledge: Volunteered Geographic Information (VGI) in Theory and Practice. Springer Berlin, 105-122.

Hansson, K., Belkacem, K.,\& Ekenberg, L. (2015). Open Government and Democracy: A Research Review, Social Science Computer Review, 33(5) 540-555.

Hassan, Z., \& Bojer, M. (2005) The Change Lab Fieldbook.

Hassan, Z. (2014). The social labs revolution: a new approach to solving our most complex challenges: Berrett-Koehler Publishers.

Hemphälä, J., Magnusson, M. (2012). Networks for Innovation - But What Networks and What Innovation? Creativity and Innovation Management, 21 (1), 3-16.

Hill, D. (2015) Why our new Urban Innovation Centre is a step towards building better cities, Guardian Cities, Retrieved April 07, 2016 from: http://www.theguardian.com/cities/2015/mar/17/urban-innovation-centre-futurecities-catapult-dan-hill-vince-cable

Howe, J. (2006). The rise of crowdsourcing. Wired magazine, 14(6), 1-4.

Huijboom, N., \& Van den Broek, T. (2011). Open data: An international comparison of strategies. European Journal of ePractice, 12(1), 4-16.

Janssen, M., Charalabidis, Y., \& Zuiderwijk, A. (2012). Benefits, adoption barriers and myths of open data and open government. Information Systems Management, 29(4), 258-268.

Jeppesen, L.B., \& Lakhani, K.R. (2010). Marginality and problem solving effectiveness in broadcast search. Organization Science, 21, 1016-1033.

Kimbell, L. (2015). Applying Design Approaches to Policy Making: Discovering Policy Lab. Brighton: University of Brighton.

Kittur, A., Chi, E. H., \& Suh, B. (2008). Crowdsourcing user studies with Mechanical Turk. In Proceedings of the SIGCHI Conference on Human Factors in Computing Systems (CHI '08). ACM, New York, NY, USA, 453-456

Kobori, H., Dickinson, J. L., Washitani, I., Sakurai, R., Amano, T., Komatsu, N., Kitamura, W., Takagawa, S., Koyama, K., Ogawara, T., \& Miller-Rushing, A. J. (2015). Citizen science: a new approach to advance ecology, education, and conservation, Ecological Research, 31 (1),pp. 1-19

Korpela, E., Siemion, A. P. V., Werthimer, D., Lebofsky, M., Cobb, J., Croft, S., \& Anderson, D. (2015). The next phases of SETI@home, Proc. SPIE 9606, Instruments, Methods, and Missions for Astrobiology XVII, 96060B

Laursen, K., \& Salter, A. J. (2014). The paradox of openness: Appropriability, external search and collaboration. Research Policy, 43(5), 867-878.

Lee, G., \& Kwak, Y. H. (2012). An Open Government Maturity Model for social media-based public engagement, Government Information Quarterly, 29 (4), 492503.

Legard, R., Keegan, J., \& Ward, K. (2003). In-depth interviews. Qualitative research practice: A guide for social science students and researchers, 138-169.

Leiblein, M.J., \& Macher, J.T. (2009). The problem solving perspective: a strategic approach to understanding environment and organization. Advances in Strategic 
Management, 26, 1-24.

Leifer, R. (2000). Radical innovation: How mature companies can outsmart upstarts. Harvard Business Press.

Leminen, S. (2013). Coordination and participation in living lab networks, Technology Innovation Management Review, 3(11).

Leminen, S., Westerlund, M., \& Nyström, A. G. (2012). Living Labs as openinnovation networks, Technology Innovation Management Review, 2(9).

Li, W. (2011). Self-motivated versus forced disclosure of environmental information in China: A comparative case study of the pilot disclosure programmes. The China Quarterly, 206, 331-351.

Madsen, T., Woolley, J., \& Sarangee, K. (2012). Using Internet-based collaboration technologies for Innovation: crowdsourcing vs. expertsourcing, Academy of Management Annual Meeting, Boston.

Magadley, W., \& Birdi, K. (2009). Innovation labs: an examination into the use of physical spaces to enhance organizational creativity. Creativity and Innovation Management, 18(4), 315-325.

Majchrzak, A. \& Malhotra, A. (2013). Viewpoint: Towards an information systems perspective and research agenda on crowdsourcing for innovation. Journal of Strategic Information Systems, 22, 4, 257-268.

Martinko, M. J., \& Gardner, W. L. (1985). Beyond structured observation: Methodological issues and new directions. Academy of Management Review, 10(4), 676-695.

Masters, K.,Lintott, C.,Feldt, J., Keel, B., \& Skibba, R. (2015). Galaxy Zoo: Science and Public Engagement Hand in Hand, IAU General Assembly, Meeting \#29, id.2225804, AAS

Miles, M. B., \& Huberman, A. M. (1994). Qualitative data analysis: An expanded sourcebook. Sage.

Mintzberg, H. (1970). Structured observation as a method to study managerial work. Journal of Management Studies, 7(1), 87-104.

Mohamed, M., \& Deepak, G. 2013. Labor dynamics in a mobile micro-task market. In Proceedings of the SIGCHI Conference on Human Factors in Computing Systems (CHI '13). ACM, New York, NY, USA, 641-650.

Murray, F., \& O'Mahony, S. (2007). Exploring the foundations of cumulative innovation:implications for organization science. Organization Science, 18 (6), 1006-1021.

Neyland, D. (2007). Organizational ethnography: Sage.

Lewis, M., \& Moultrie, J. (2005). The Organizational Innovation Laboratory. Creativity and Innovation Management, 14(1), 73-83.

Li, L. C., Grimshaw, J. M., Nielsen, C., Judd, M., Coyte, P. C., \& Graham, I. D. (2009). Evolution of Wenger's concept of community of practice. Implementation science, 4(1), 11.

Oksanen, K., \& Ståhle, P. (2013). Physical environment as a source for innovation: investigating the attributes of innovative space. Journal of knowledge 
management, 17(6), 815-827.

Open Government Partnership. (2016). Retrieved April 02, 2016, from http://www.opengovpartnership.org/

Open Government Progress Report to the American People. (2009). White House web page. Retrieved April 01, 2016, URL, http://www.whitehouse.gov/sites/default/files/microsites/ogi-progress-reportamerican-people.pdf

Open Science collaboration (2015). Estimating the reproducibility of psychological science, Science, 349 (6251).

Open Science Collaboration (2012). An Open, Large-Scale, Collaborative Effort to Estimate the Reproducibility of Psychological Science, Perspectives on Psychological Science, 7(6), 657-660.

Owens, B., (2016) Montreal institute going 'open' to accelerate science, Science, 22, 329.

Pittaway, L., Robertson, M., Munir, K., Denyer, D., \& Neely, A. (2004). Networking and innovation: a systematic review of the evidence. International Journal of Management Reviews, 5(3-4), 137-168.

Prahalad, C. K., \& Ramaswamy, V. (2013). The future of competition: Co-creating unique value with customers: Harvard Business Press.

Puttick, R. (2014). Innovation Teams and Labs - A Practice Guide: Nesta. Retrieved from

http://www.nesta.org.uk/sites/default/files/innovation teams and labs a practic e guide.pdf

Puttick, R., Baeck, P., \& Colligan, P. (2014). i-teams. The teams and funds making innovation happen in governments around the world: Nesta.

Reos Partners (2013). Reos Change Lab - Addressing Complex Challenges with Social Innovation: Innoweave Knowledge Sharing Platform \& the J.W. McConnell Family Foundation

Robinson, D., Yu, H., Zeller,W. P., \& Felten, E. W. (2009). Government data and the invisible hand. Yale Journal of Law and Technology, 11(1), Article 4.

Rowe, P. G. (1991). Design thinking: MIT press.

Schot, J., \& Geels, F. W. (2008). Strategic Niche Management and Sustainable Innovation Journeys: Theory, Findings, Research Agenda, and Policy. Technology Analysis \& Strategic Management, 20(5), 537-54.

Shostack, G. L. (1982). How to design a service. European Journal of Marketing, $16(1), 49-63$.

Schuurman, D. (2015). Bridging the gap between Open and User Innovation?: exploring the value of Living Labs as a means to structure user contribution and manage distributed innovation, Doctoral dissertation, Ghent University.

Schuurman, D., Marez, L. D., \& Ballon, P. (2016). The Impact of Living Lab Methodology on Open Innovation Contributions and Outcomes. Technology Innovation Management Review, 1(6), 7-16. 
Simula, H., \& Ahola, T. (2014). A network perspective on idea and innovation crowdsourcing in industrial firms. Industrial Marketing Management, 43 (3), 400408.

Stanford Crowd Research Collective (2015). Daemo: A Self-Governed Crowdsourcing Marketplace. Adjunct Proceedings of the 28th Annual ACM Symposium on User Interface Software \& Technology, 101-102,

Strathern, M. (2000). The tyranny of transparency. British Educational Research Journal, 26(3), 309-321.

The Comms Lab (2016). Why? The Comms Lab website, accessed on 7 April 2016, URL: http://thecommslab.com/about/\#why

Thompson, J. R., \& Sanders, R. P. (Eds.). (1998). Transforming government: Lessons from the reinvention laboratories. Jossey-Bass Incorporated Pub.

Tiesinga, H., \& Berkhout, R. (2014). Labcraft. How social labs cultivate change through innovation and collaboration. London \& San Francisco: Labcraft Publishing.

Toivonen, T. (2016). What is the Social Innovation Community? Conceptualizing an Emergent Collaborative Organization. Journal of Social Entrepreneurship, 7 (1), 49-73.

Toivonen, T. \& Friederici, N. (2015). Time to define what a "hub" really is. Stanford Social Innovation Review, 14 April 2015 (online article).

Toivonen, T., Friederici, N., Gryszkiewicz, L., Edwards, M., \& Jimenez, A. (2016). On Collaborative Innovation Intermediaries, in Making Utopias Real: Social Innovation, Movements and Change. EGOS, 7-9 July 2016, Naples.

Tõnurist, P., Kattel, R. \& Lember, Veiko, (2015), Discovering Innovation Labs in the Public Sector, The Other Canon, Foundation and Tallinn University of Technology Working Papers in Technology Governance and Economic Dynamics, TUT Ragnar Nurkse School of Innovation and Governance, URL: http://EconPapers.repec.org/RePEc:tth:wpaper:61.

Unicef (2012). Innovation Labs. A Do-It-Yourself Guide (pp. 125).

United Nations Division for Public Administration and Development Management. (2013). Guidelines on open government data for citizen engagement. Retrieved April 01, 2016, from:

http://workspace.unpan.org/sites/Internet/Documents/Guidenlines\%20on\%200 GDCE\%20May17\%202013.pdf

Vaish, R, Davis, J, \& Bernstein, M. (2015), Crowdsourcing the Research Process, Collective Intelligence 2015, Santa Clara, CA

von Hippel, E. (2009). Democratizing innovation (Vol. 1). Cambridge (Massachusetts) \& London (England): The MIT Press.

von Hippel, E. (2007). Horizontal innovation networks-by and for users. Industrial and Corporate Change, 16 (2), 293-315.

von Hippel, E., Von Krogh, G. (2006). Free revealing and the private-collective model for innovation incentives. R\&D Management, 36 (3), 295-306.

von Hippel, E. (2005). Democratizing Innovation. MIT Press, Cambridge, MA. 
Wenger, E. C., \& Snyder, W. M. (2000). Communities of practice: The organizational frontier. Harvard Business Review, 78(1), 139-146.

West, J., Salter, A., Vanhaverbeke, W., \& Chesbrough,H. (2014) Open innovation: The next decade, Research Policy, 43(5), 805-811.

West, J., \& Lakhani, K.R. (2008). Getting clear about communities in open innovation. Industry and Innovation, 15 (2), 223-261

Westley, F., Laban, S., Rose, C., McGowan, K., Robinson, K., Tjornbo, O., \& Tovey, M. (2014). Social Innovation Lab Guide. Retrieved from http://networkingaction.net/wp-content/uploads/10 silabguide final.pdf

Ye, H., Kankanhalli, A., Huber, M., Bretschneider, U., Blohm, I., Gaswami, S., Leimeister, J., \& Krcmar, H. (2012). Collaboration and the quality of user generated ideas in online innovation communities. Annual Academy of Management Meetings, August, Boston.

Yin, R. K. (2009). How to do better case studies. The SAGE handbook of applied social research methods, 2, 254-282. 


\section{Appendices}

Appendix 1: Innovation lab websites used for labs' self-discourse analysis.

Name Website

BRAC Social Innovation Lab http://innovation.brac.net/

(SIL)

\begin{tabular}{ll}
\hline Campaign Lab & http://campaignlab.org.uk/about/ \\
\hline Civic Innovation Lab & http://www.civicinnovationlab.la/\#section-0 \\
\hline eLab & http://www.rmi.org/elab \\
\hline EvergreenCityWorks & http://www.evergreen.ca/ \\
\hline FreedomLab & http://www.freedomlab.org/\#!contact/con8 \\
\hline Global Knowledge Initiative & http://www.globalknowledgeinitiative.org \\
\hline inCompass Human-Centered & http://www.incompass.org/?page_id=29 \\
Innovation Lab & \\
\hline Innovation Co-creation Lab & http://icclab.com/ \\
\hline Innovation Growth Lab & http://www.innovationgrowthlab.org/ \\
\hline Innovation Labs & http://www.innovationlabs.org.uk/start-here/ \\
\hline InnovationLab & http://www.innovationlab.de/en/innovationlab/ \\
\hline InSTEDD's Innovation Labs & http://instedd.org/ilabs/ \\
(aka iLabs) & \\
\hline La 27e Région & http://blog.la27eregion.fr/ \\
\hline Laboratory for the City & http://labplc.mx/complices/ \\
\hline (Mexico) & \\
\hline MaRS Solutions Lab & https://www.marsdd.com/systems-change/mars-solutions-lab/ \\
\hline MindLab & http://mind-lab.dk/en/om-mindlab/ \\
\hline Nutrition Innovation Lab & http://www.nutritioninnovationlab.org/ \\
\hline Sustainable Food Laboratory & http://www.sustainablefoodlab.org/ \\
\hline The Civic Systems Lab & http://www.civicsystemslab.org/contactus/ \\
\hline The Comms Lab & http://www.thecommslab.com/ \\
\hline The Finance Innovation Lab & http://www.thefinancelab.org \\
\hline Sustainable Transition Lab & http://www.socialinnovationlab.net/ \\
\hline Qune Stanford Change Labs & http://changelabs.stanford.edu/ \\
\hline Unicef Innovation Labs & http://quartierstuff.lu \\
\hline
\end{tabular}




\section{Appendix 2: Interview details and duration}

- IDEA (face-to-face, 51 minutes excl. intro \& closing)

- Fab Lab London (face-to-face, approx. 60 minutes, excluded from the sample as not relevant)

- Fab Lab Luxembourg (face-to-face, approx. 45 minutes, excluded from the sample as not relevant)

- GovLabs (face-to-face, approx. 45 minutes excl. intro \& closing - not recorded)

- Innovation Labs (Skype, 50 minutes excl. intro \& closing)

- Innovation Co-Creation Lab (face-to-face, 38 minutes excl. intro \& closing)

- Living Lab Lux. (phone, approx. 30 minutes excl. intro \& closing, excluded from the sample as not relevant)

- Nesta Innovation Growth Lab (face-to-face, 55 minutes excl. intro \& closing)

- Nesta Innovation Lab (face-to-face, 55 minutes excl. intro \& closing)

- mHealthHabitat (now mHabitat) Lab London (face-to-face, 76 minutes excl. intro \& closing)

- mHealthHabitat (now mHabitat) Lab Leeds (Skype, 34 minutes excl. intro \& closing)

- $\quad$ RSA the Great Recovery (face-to-face, approx. 90 minutes excl. intro \& closingnot recorded)

- Future Cities Catapult (face-to-face, approx. 90 minutes excl. intro \& closing- not recorded)

- The Comms Lab (face-to-face, 51 minutes excl. intro \& closing)

- The Civic Systems Lab (face-to-face, 39 minutes excl. intro \& closing)

Appendix 3: Semi-structured interview guide

Intro: introduce ourselves and the purpose of our study, ask for permission to record the interview and explain the data treatment

Please introduce yourself and your role in the organisation

What is the main purpose of [your innovation lab]?

What is the main challenge it addresses?

Who is the driving force behind this lab?

Who are the actors participating in the co-creation?

What are their key collaborative practices?

Which methodologies do you use to guide this process?

What are the main challenges practitioners face in collaborative innovation?

What is the role of technologies in collaborative innovation? And how much of collaborative innovation success conversely depends on non-technological factors?

What challenges do currently still remain unresolved?

What are some examples of projects that have recently been launched at your lab?

Which prior projects do you consider most successful or interesting?

What types of teams, leaders or facilitators have carried these projects forward? 
Which backgrounds and areas of expertise have participated in these teams?

How would you define an innovation lab in general and how would it differ from other forms? 